\title{
Changes in maternal conception about breastfeeding
}

\author{
Aline Elizabeth da Silva 1 \\ Cássia Olívia Machado Campos 2 \\ Maria do Carmo Fontes de Oliveira 3 \\ Andréia Queiróz Ribeiro 4 \\ Rosângela Minardi Mitre Cotta 5 \\ Raquel Maria Amaral Araújo 6
}

\footnotetext{
1 Programa de Pós-Graduação em Enfermagem. Escola de Enfermagem. Universidade Federal de Minas Gerais. Av. Alfredo Balena, 190. Santa Efigênia. Belo Horizonte, MG, Brasil. CEP: 30.130-100. E-mail: alineesnutri@hotmail.com

2 Nutricionista da Prefeitura de Ubá. Ubá, MG, Brasil.

3-6 Departamento de Nutrição e Saúde. Centro de Ciências Biológicas e da Saúde. Universidade Federal de Viçosa. Viçosa, MG, Brasil.
}

\begin{abstract}
Objectives: to analyze maternal conceptions about the conditions of stimulating and discouraging breastfeeding before and after the educational intervention.

Methods: An intervention study type pretest/posttest was conducted for 113 women attended at a public health service. An adapted cross-cultural questionnaire was applied to identify the conceptions of pregnant women about the conditions of stimulating and discouraging breastfeeding. The effect of the intervention was verified by assessing the Decisional Balance scores before and after the intervention.

Results: there was a reduction in the overall score of the discouraging conditions and an increase of the overall score of the stimulating conditions $(p<0.001)$. In evaluating each discouraging condition, a significant reduction in the affirmative scores was observed as "breastfeeding makes the breasts saggy" ( $p=0.003)$, "I think my breasts are too small to have enough breast milk for my baby" ( $p=0.001)$. Regarding to the stimulating conditions, it showed a significant increase in the affirmative score for "breastfeeding is good for me" ( $p=0.006)$, "breastfeeding can help me lose weight" ( $p=0.013)$, "breastfeeding is easy" $(p=0.004)$.

Conclusions: the intervention resulted in changing maternal conceptions of breastfeeding and can be an interesting strategy on promoting breastfeeding in health services.
\end{abstract}

Key words Breastfeeding, Maternal behavior, Intervention studies 


\section{Introduction}

Breastfeeding is recognized as a complex practice and is permeated by social, political, historical and cultural as myths, beliefs and values have been passed on throughout generations, ${ }^{1}$ and can influence on the women's decision to breastfeed or not and the duration of this practice. ${ }^{2}$

Among the factors that hinder the initiation of breastfeeding or that leads to the interruption are those related to the mother and additionally, cultural. ${ }^{2}$ Regarding to the mother, her intention to breastfeed stands out and also the confidence in her ability to breastfeed. ${ }^{3}$ In virtue of the variety of social and cultural factors that influences this behavior in deciding to breastfeed is not always a calm scenario for women, ${ }^{1}$ and manifests even in the gestational period. Thus, prenatal consultation is the most suitable moment to promote breastfeeding. 3,4

The strategies developed in Brazil for promoting breastfeeding has resulted improvements in its rates, however it still requires a large commitment of those involved with the issue on infant nutrition to achieve levels compatible to the recommendation of the World Health Organization (WHO). 5 A part of this effort involves the development of educational interventions in health services that promote the initiation and continuation of breastfeeding. 6

The women's conception on the contrary to breastfeeding is considered an influential factor on decision making to implement this practice. ${ }^{7}$ For this reason, the activities to promote breastfeeding during the prenatal period may result in greater success when conducted from a prior investigation among women on their concepts about the conditions of stimulating and discouraging breastfeeding. 8 Thus, it is necessary to carry out the intervention studies to promote breastfeeding that include the investigation of maternal conception about this behavior. This present study proposes an intervention strategy based on the Decisional Balance construct. 9 The Decisional Balance construct reflects on the weight of the individual's conception about the positive and negative consequences, the socalled pros and cons, the adoption of the desirable behavior. 10 The evaluation of this construct assists in the elaboration of the strategies for the individual to adopt the desirable behavior. ${ }^{10}$ Humphreys et al. 11 adapted the Decisional Balance construct to be used in the assessment of the pregnant women's concept about the conditions of stimulating and discouraging breastfeeding with the purpose of promoting the achievement of strategies in favor of breastfeeding among pregnant women are more efficient.
Considering the interventions that are more efficient when directed and supported by a theoretical model, 11 the purpose of this study is to contribute in improving actions in health services to assist breastfeeding and as a privilege in identifying maternal conception on breastfeeding. Therefore, the objective of this study was to analyze the mother's conceptions about the conditions of stimulating and discouraging breastfeeding before and after the educational intervention.

\section{Methods}

An intervention study type pre-test/posttest was conducted, whereas the individual is of her own control.12 Thus, the assessment of the Decisional Balance construct occurred in the before and after intervention period.11,13 113 women were attended at a Primary Health Care (UAPS) in Viçosa, MG, between June 2013 and September 2014.

There was an estimate of 127 pregnant women in each group, considering the national prevalence of exclusive maternal breastfeeding in children younger than six months of $41 \% 14$; there was an increase of $20 \%$ in this prevalence to the group who received the intervention 15 ; confidence level of $95 \%$ and the study power is equal to $80 \%$. An increase of an estimated number of $30 \%$ for probable losses to the follow-up, once the intervention study requires more meetings, therefore, more chances of participants' to abandon. The prevalence for exclusive breastfeeding was used in the calculation of the sample, since this study is part of a larger project and the main outcome was about the behavior cited. So far, there are no similar studies to serve as a basis for the calculation. By chance, the selected sample included all the pregnant women who were in the waiting room at the healthcare units waiting for medical assistance at the moment and they agreed to participate in this study. Pregnant women with positive HIV test were excluded from the sample for having a condition that is impeded to breastfeed. 16

Of the 127 pregnant women who started in this study in the prenatal care, 113 women completed the study, resulting in $11.0 \%$ of loss to the follow up. The main reason of losses was the difficulty to contact the participants by phone. The analysis of the losses showed no statistically significant differences between the groups in relation to socioeconomic, demographic and previous experience in breastfeeding (data not shown)

For the assessment of the Decisional Balance, a translated and adapted questionnaire by Campos 13 was used, following the adapted stages from Beaton 
et al. 17 and Reichenheim and Moraes. ${ }^{18}$ Thus, the validity of this content was considered satisfactory and also the equivalences of semantic, conceptual, item, operational and measurement. This questionnaire identified the pros and cons of breastfeeding, 13 denominated in this study, respectively, as "conditions of stimulus" and "conditions of discouragement" for breastfeeding in order to facilitate the understanding of the object being analyzed. As the participants were instructed to indicate their degree of agreement or disagreement in relation to the twenty questions, of these twenty, ten discouraged breastfeeding, by using the five points of Likert scale (totally disagree, disagree, neither agree nor disagree, agree and strongly agree). The overall score of stimulating and discouraging conditions could vary from 10 to 50 . In the evaluation of each affirmative sentence, a score of less than four indicated that the woman disagreed with this affirmative statement, and a score equal or greater than four indicated that the woman agreed with this affirmative statement. This cut-off point was adopted considering the four score of Likert scale and so on, corresponding to the woman's agreement with the statement presented in the questionnaire. This questionnaire was applied in the prenatal care before and after the intervention, within the first 15 days after postpartum. Also, the data collected were related to socioeconomic, demographic, obstetric conditions and past experience of breastfeeding, through interviews in a semi-structured questionnaire.

For the implementation of the individual interventions, a flip chart and brochures with pictures and the use of appropriate language for this specific audience were developed. The flip chart included the following topics: the benefits of breastfeeding for the mother-baby; the differences among breast milk, infant formula and cow milk; physiological process of the production of breast milk, breastfeeding on free demand; the baby's gastric capacity; positions for breastfeeding and handling; preventing and solving problems of the nipples; manual on milking; myths in relation to breastfeeding and among others. The informative leaflets on the dangers of using the bottle and the nutritional differences among breast milk, infant formula and porridges. A doll and breast models were also used ("experimental breasts").

The educational strategy used was the individualized dialog, and the themes dealt with each pregnant woman were defined from the result of the Decisional Balance assessment. Those pregnant women who agreed with the discouraging statement for breastfeeding and/or disagreed with an affirmative of stimulating breastfeeding were guided in overcoming the identified barriers. 19 The research team was able to perform counseling, which is recommended by the World Health Organization (WHO) ${ }^{20}$ and aims to listen to the woman, understand her, support and help her in the decision making to increase their self-confidence and selfesteem.

The meetings with the pregnant women were monthly. They occurred during the prenatal care, before the medical consultation and in the waiting rooms of the health units. The average of the meetings was about three, ranging from one to eight meeting per month with an approximate duration of 10 minutes. This variation is due to the fact that the study was conducted with pregnant women in the first and the third quarter. The guidelines followed the contents in the flip chart emphasizing the issues related to the conditions of discouragement pointed out by the pregnant women in the Decisional Balance assessment. In each new meeting, the themes were reworked on to clarify the possible doubts still present and/or new necessities identified by the pregnant woman. Considering the possible influence of the variable number of meetings in the results of this study, an analysis was conducted to compare the result of the Decisional Balance assessment between women who participated in one meeting and those who participated in two or more meetings and there were no significant differences. In addition, for the analyzes of this study, all the women were included, regardless of the number of meetings.

In the after intervention phase, the researchers reapplied the questionnaire for the Decisional Balance construct in order to evaluate the changes in the conception of breastfeeding. The interval between the pre and posttest ranged from 30 to 60 days. This phase occurred in the postpartum period, especially during the first 15 days of the newborn's life at the immunization sector of the town at the occasion of the Guthrie test. If there was the impossibility of the mother to meet and answer the questionnaire, the interview could be held at home visits or by telephone, it was the nursing mother's decision.

The normality of the variables was verified by the Kolmogorov-Smirnov test. Measurements of frequency were used in the central tendency and the dispersion of the participants' characteristics description. The values of the Decisional Balance scores of the before and after intervention were compared by using the Wilcoxon test. The effect of the intervention was evaluated by the means of verifying changes in maternal behavior, in other words, 
the evaluation of the Decisional Balance construct was performed of the before and after intervention.

In all the analyzes, the significance level was set at $5 \%$. The statistical analyzes were performed with the aid of the Statistical Package for Social Science (SPSS) for Windows version 22.0 program.

The participation was performed by signing the Informed Consent Form. This study was approved by the Ethics Committee in Human Research at Universidade Federal de Viçosa in Minas Gerais, accredited by the National Health Council, under the documented number 412.814/2013.

\section{Results}

The socioeconomic and demographic characteristics and the relation to breastfeeding samples are described in Table 1. Approximately two thirds of the participants were adults, the mean age was 24.1 years; $92.0 \%$ graduated from high school and $72.0 \%$ had a companion. Most of them do not have a paid job, one stated the per capita income of R\$339.00 and was a primiparous. In terms of the variables related to maternal breastfeeding, $86.0 \%$ of the women were breastfed and about a third had previous experience in breastfeeding longer than 24 months.

Table 2 shows a significant reduction in the overall score of discouragement and a significant increase in the overall score of stimulating conditions after the intervention $(p<0.001)$.

When comparing the mean scores for each stimulus condition and discouraging condition to breastfeeding the before and after intervention (Table 3), significant differences in four discouraging conditions and six stimulating conditions were observed.

The scores of discouragement were

Table 1

Socioeconomic and demographic characteristics and related to breastfeeding of pregnant women participating in this study. Viçosa, MG, 2013-2014.

\begin{tabular}{|c|c|c|}
\hline Characteristics & $N=113$ & $\%$ \\
\hline \multicolumn{3}{|l|}{ Age (years) } \\
\hline$<20$ & 39 & 34.5 \\
\hline$\geq 20$ to 34 & 65 & 57.5 \\
\hline$\geq 35$ & 9 & 8.0 \\
\hline \multicolumn{3}{|l|}{ Schooling (years) } \\
\hline $0-4$ & 5 & 4.4 \\
\hline $5-8$ & 38 & 33.6 \\
\hline $9-11$ & 61 & 54.0 \\
\hline$\geq 12$ & 9 & 8.0 \\
\hline \multicolumn{3}{|l|}{ Marital status } \\
\hline With a partner & 81 & 71.7 \\
\hline Without a partner & 32 & 28.3 \\
\hline \multicolumn{3}{|l|}{ Does mother work } \\
\hline Yes & 48 & 42.5 \\
\hline No & 65 & 57.5 \\
\hline \multicolumn{3}{|c|}{ Income per capita $(\mathrm{n}=111)$} \\
\hline$\leq 1 / 2 \mathrm{MW}$ & 60 & 54.1 \\
\hline$>1 / 2 \mathrm{MW}$ & 51 & 45.9 \\
\hline \multicolumn{3}{|l|}{ Parity } \\
\hline Primiparous & 63 & 55.8 \\
\hline Multiparous & 50 & 44.2 \\
\hline \multicolumn{3}{|l|}{ Was breastfed } \\
\hline Yes & 97 & 85.8 \\
\hline No & 10 & 8.8 \\
\hline Don't know & 6 & 5.4 \\
\hline \multicolumn{3}{|c|}{ Previous experience in breast feeding } \\
\hline$<24$ months & 32 & 64.0 \\
\hline$\geq 24$ months & 18 & 36.0 \\
\hline
\end{tabular}

$\mathrm{MW}=$ minimum wage at the time of the study; $\mathrm{MW}=\mathrm{R} \$ 678.00$. 
"Breastfeeding makes the breasts saggy, I think breast milk is disgusting, I don't even think about if I don't know everything about breastfeeding and I think that my breasts are too small to have enough milk for my baby" presented after the interventions, a statistically significant reduction. However, the scores of stimulating conditions "Breastfeeding is good for me, If babies are breastfed their diapers don't smell that bad, Breastfeeding helps my uterus return to the normal size quickly, Breastfeeding helps me lose weight, Breastfeeding is easy and Breast milk is cheaper than other kind of milk" were statistically superior after the interventions.

\section{Discussion}

The educative intervention resulted in a positive impact regarding to the change in the conception of the conditions of discouraging breastfeeding. Although, the increase in the overall score for stimulating conditions reflects in the change of behavior after the educational intervention. The Decisional Balance is presumed to be based on the promotion of breastfeeding which may promote both the initiation of breastfeeding in the postpartum period as the extension of this practice. According to Tung et al.,21 to alter the conception about the conditions of discouragement to the desired behavior can result in the effects of long duration of this behavior. After an extensive literature review, there has been no studies investigating the effect of the interventions based on the Decisional Balance in relation to breastfeeding, however Salehi et al.22 demonstrated a reduction in the conception of the discouraging conditions by increasing the consumption of fruit and vegetables for elderly Iranians.

The Decisional Balance construct assessment contributed to the knowledge of the interfering factors in the decision making process of breastfeeding in the studied group. The result highlights for the condition of discouragement "Breastfeeding makes the breasts saggy", considering that one of the difficulties to breastfeed is the concern with the appearance of the breasts. ${ }^{23}$ It is evident, therefore, the effect of the intervention for women to understand the relation of breastfeeding and the appearance of the breasts, making them feel safer about their decision on breastfeeding. ${ }^{24}$ It is noteworthy that the intervention improved the understanding about the interference of breast size with the volume of milk produced.

The conception that human breast milk is disgusting 25 may influence the maternal attitude in relation to breastfeeding. Although breast milk has been recognized as a healthy food for most, a part of them agreed with the statement that breast milk is referred to something disgusting. This conception can be related to certain cultural contexts, 26 however the intervention favored a positive experience in these pregnant women by making them change their concept about breast milk, thus overcoming cultural influences. This result shows that it is possible to modify concepts that are culturally constituted and represent conditions of discouraging breastfeeding.

The mean reduction in the score of the discouraging condition "I don't even think about if I don't know everything about breastfeeding" may indicate that the intervention increased these women's level of knowledge about breastfeeding, giving them more confidence and autonomy. This result is relevant according to Susiloretni et al.27 of the high level of knowledge about breastfeeding is positively associated to the duration of exclusive breastfeeding.

The participants agreed with a large number of

Table 2

General scores of stimulating conditions and discouraging breastfeeding in the before and after intervention. Viçosa, MG, 2013-2014

\begin{tabular}{|c|c|c|c|}
\hline & Before intervention & After intervention & $p^{*}$ \\
\hline & $\bar{X} \pm S D$ & $\bar{X} \pm S D$ & \\
\hline Discouraging conditions & $28.12 \pm 3.11$ & $26.84 \pm 3.37$ & $<0.001$ \\
\hline Stimulating conditions & $39.43 \pm 2.43$ & $41.19 \pm 3.42$ & $<0.001$ \\
\hline
\end{tabular}

*Comparisons of before and after intervention: Wilcoxon Test. 
Table 3

Scores of the discouraging and stimulus conditions for breastfeeding in the before and after intervention. Viçosa, MG, 2013-2014.

\begin{tabular}{ccc} 
Before intervention & After intervention & $\boldsymbol{p}^{*}$ \\
\hline $\bar{X}_{ \pm S D}$ & $\bar{X}_{ \pm S D}$
\end{tabular}

\section{Discouraging conditions}

To breastfeed is "out of fashion", "tacky"

To breastfeed means that nobody else can do it for me, I have to be ready for the child

To breastfeed means that $i$ have to change my eating habits

I would be embarrassed if someone saw me breastfeeding

To breastfeed means the breast will sag

I think breast milk is disgusting

I think breastfeeding is painful

To breastfeed means that I cannot return to work or study

I don't even think about that I don't know everything about breastfeeding

I think that my breasts are too small to have enough milk for my baby

$\begin{array}{ll}1.72 \pm 0.51 & 1.71 \pm 0.46 \\ 3.96 \pm 0.80 & 3.99 \pm 0.79 \\ 3.68 \pm 0.93 & 3.76 \pm 0.82 \\ 2.01 \pm 0.83 & 1.94 \pm 0.71 \\ 2.94 \pm 1.01 & 2.57 \pm 1.00 \\ 2.35 \pm 0.91 & 2.12 \pm 0.80 \\ 2.94 \pm 1.08 & 2.90 \pm 1.05 \\ 2.18 \pm 0.80 & 2.12 \pm 0.84 \\ 3.92 \pm 0.75 & 3.63 \pm 0.80 \\ 2.42 \pm 1.02 & 2.10 \pm 0.87\end{array}$

\section{Stimulating conditions}

Breast milk is the healthiest food for the baby

I think that breastfeeding is good for the baby

To breastfeed is good for me

If babies are breastfed their diapers don't smell that bad

To breastfeed may help me feel closer to my baby

To breastfeed helps protect my baby against diseases and allergies.

$4.42 \pm 0.50$

$4.43 \pm 0.50$

$4.32 \pm 0.47$

$4.28 \pm 0.45$

$4.00 \pm 0.71 \quad 4.19 \pm 0.41$

$3.24 \pm 0.82 \quad 3.65 \pm 0.78$

$4.34 \pm 0.47 \quad 4.30 \pm 0.52$

$4.35 \pm 0.53 \quad 4.40 \pm 0.49$

$4.14 \pm 0.46$
$4.00 \pm 0.60$

To breastfeed helps my uterus return to the normal size quickly

To breastfeed may help me lose weight

$3.80 \pm 0.75$

$3.15 \pm 0.97$

$4.00 \pm 0.60$
$3.42 \pm 0.92$

Breast milk is cheaper than the any other milk

$4.23 \pm 0.64$

$4.38 \pm 0.63$ 
stimulating conditions to breastfeed, which can be in favor the adoption of this practice. ${ }^{28}$ Another important aspect was the fact that the women acknowledged the benefits of breastfeeding for their health, since women tend to assign less to significant advantages related to maternal health. 7,29

Despite the significant increase in the mean scores after the intervention, the nursing mothers did not agree with the statement "If babies are breastfed their diapers don't smell that bad" indicating that this perception of smell probably does not influence on the educational intervention. They, too, did not consider that "Breastfeeding is easy", suggesting that the educational intervention could help a woman to solve problems, but the perception that breastfeeding is a difficult task remains.

Considering that $54 \%$ of the sample had a lower per capita income of two minimum wages, which is noteworthy to mention that the increase in the mean score of the statement is related to the economic benefits of breastfeeding. A study that compared the cost of complementary feeding of a nursing mother

\section{References}

1. Moreira MA, Nascimento ER, Paiva MS. Representações sociais de mulheres de três gerações sobre práticas de amamentação. Texto Contexto Enferm. 2013; 22: 432-41.

2. Peres PLP, Pegoraro AO. Condições desiguais como causas para a interrupção do aleitamento materno. Rev Enferm UERJ. 2014; 22: 278-85.

3. Díaz-Gómez M, Martínez MR, Ares S, Espiga I, Alba C. Motivaciones y barreras percibidas por lãs mujeres españolas en relación a la lactancia materna. Rev Esp Salud Pública. 2016; 90; 1-18.

4. Nascimento VC, Oliveira MIC, Alves VH, Silva KS Associação entre as orientações pré-natais em aleitamento materno e a satisfação com o apoio para amamentar. Rev Bras Saúde Mater Infant. 2013; 13: 147-59.

5. Wenzel D, Souza SB. Prevalência do aleitamento materno no Brasil segundo condições socioeconômicas e demográficas. Rev Bras Crescimento Desenvolv Hum. 2011; 21: $251-8$.

6. WHO (World Health Organization). Global strategy for infant and young child feeding. Geneva; 2009.

7. Radzyminski S, Callister LC. Mother's beliefs, attitudes, and decision making related to infant feeding choices. J Perinat Educ. 2016; 25: 18-28.

8. Besore CT. Barriers to breastfeeding for hispanic mothers Breastfeed Med. 2014; 9: 352-4.

9. Prochaska JO, Diclemente CC. Transtheoretical terapy: toward a more integrative model of change. Physiother Theory Pract. 1982; 19: 276-88.

10. Rossi SR, Greene GW, Rossi JS, Plummer BA, Benisovich SV, Keller S, Velicer WF, Redding CA, Prochaska JO, PAllonen UE, Meier KS. Validation of decisional balance in relation to baby food supply to substitute breast milk, but breast milk showed that is cheaper and more effective to provide than supplemental feeding for nursing mothers in need, so that the nursing mother could breastfeed rather than receive the distribution of infant formula or milk, and encouraging early weaning. 30

A limitation of this study was the difficulty to maintain a frequency of meetings with the pregnant women. As these meetings were held before the medical consultation, its occurrence depended on the frequency of the professional at the service. Given the organizational characteristics of work at the health units, such as absence of substitutes to cover physicians' vacation or the terminal of the contracts, this jeopardized the continuation of meetings in some UAPS when there was no medical consultation.

The intervention based on the Decisional Balance construct resulted in a change of perceptions on maternal breastfeeding and can be a promising strategy to promote breastfeeding in health services. and situational temptations measures for dietary fat reduction in a large school-based population of adolescents. Eat Behav. 2001; 2: 1-18.

11. Humphreys AS, Thompson NJ, Miner KR. Assessment of breastfeeding intention using the Transtheoretical Model and the Theory of Reasoned Action. Health Edu Res. 1998; 13: 331-41.

12. Bonate PL. Analysis of pretest-posttest designs. Flórida: Boca Raton: Chapman \& Hall/CRC; 2000

13. Campos COM. Modelo Transteórico para Mudança de Comportamento frente à amamentação nos serviços públicos de saúde. [dissertação]. Viçosa (MG): Universidade Federal de Viçosa; 2014.

14. Brasil. Ministério da Saúde. Secretaria de Atenção à Saúde. Departamento de Ações Programáticas e Estratégicas. II Pesquisa de Prevalência de Aleitamento Materno nas Capitais Brasileiras e Distrito Federal. Brasília, DF; 2009.

15. Susin LRO, Giugliani ERJ, Krummer SC, Maciel M, Benjamin ACW, Machado DB, Barcaro M, Draghetti V. Uma estratégia simples que aumenta os conhecimentos das mães em aleitamento materno e melhora as taxas de amamentação. J Pediatr. 1998; 74: 368-75.

16. WHO (World Health Organization). Acceptable medical reasons for use of breast-milk substitutes. Geneva; 2009.

17. Beaton D, Bombardier C, Guillemin F, Ferraz MB. Recommendations for the cross-cultural adaptation of the DASH \& QuickDASH outcome measures; 2007.

18. Reichenheim ME, Moraes CL. Operacionalização de adaptação transcultural de instrumentos de aferição usados em epidemiologia. Rev Saúde Pública. 2007; 41: 665-73.

19. Prochaska JO, Diclemente CC, Norcross JC. In search of 
how people change: Applications to the addictive behaviors. Am Psychol. 1992; 47: 1102-14.

20. WHO (World Health Organization). Breastfeeding counselling: a training course. Geneva: WHO; 1993.

21. Tung WC, Farmer S, Ding K, Tung WK, Hsu CH. Stages of condom use and decisional balance among college students. Int Nurs Rev. 2009; 56: 346-53.

22. Salehi L, Mohammad K, Montazeri A. Fruit and vegetables intake among elderly Iranians: a theory-based interventional study using the five-a-day program. Nutr J. 2011; 123: $1-9$.

23. Belentani LM, Agnolo CMD, Ichisato SMT, Waidman AP, Pelloso SM. Visão de mulheres que experienciaram o aleitamento materno após implante de prótese mamária. Cogitare Enferm. 2011; 16: 254-60.

24. Coutinho ACFP, Soares ACO, Fernandes PS. Conhecimento das mães sobre os benefícios do aleitamento materno à saúde da mulher. Rev Enferm UFPE, 2014; 8: 1213-20.

25. Leite GO, Martins FDP, França MS, Ângelo BHB, Vasconcelos MGL, Pontes CM. Representações sociais de mulheres sobre o cheiro do leite materno. Esc Anna Nery. 2016; $20: 1-8$
26. Giuliani NR, Oliveira J, Santos BZ, Bosco VL. O início do desmame precoce: motivos das mães assistidas por serviços de puericultura de Florianópolis/SC para esta prática. Pesq Bras Odontoped Clin Integr. 2012; 12: 53-8.

27. Susiloretni KA, Hadi H, Prabandari YS, Soenarto YS, Wilopo SA. What Works to Improve Duration of Exclusive Breastfeeding: Lessons from the Exclusive Breastfeeding Promotion Program in Rural Indonesia. Matern Child Health J. 2014; 19: 1515-25

28. Marques ES, Cotta RMM, Priore SE. Mitos e crenças sobre o aleitamento materno. Ciên Saúde Colet. 2011; 16: 24618.

29. Martins MZ. Benefícios da amamentação para saúde materna. Interfaces Científicas-Saúde Ambiente. 2013; 1: 87-97.

30. Rollins NC, Lutter CK, Bhandari N, Hajeebhoy N, Horton S, Martines JC, Piwoz EG, Richter LM, Victora CG. Por que investir e o que será necessário para melhorar as práticas de amamentação? Epidemiol Serv Saúde, Brasília. 2016: 2544

Received on May 17, 2016

Final version presented on October 14, 2016

Approved on October 20, 2016 